\title{
Predicted Thermal Stress in Flip-Chip and Fine-Pitch-Ball-Grid-Array Designs: Effect of the Underfill Glass Transition Temperature
}

Suhir $\mathrm{E}^{1,2,3^{*}}$ and Ghaffarian $\mathbf{R}^{\mathbf{4}}$

${ }^{1}$ Departments of Mechanics and Materials, Electrical and Computer Engineering, Portland State University, Portland, USA

${ }^{2}$ Department of Electronic Materials, Technical University, Vienna, Austria

${ }^{3}$ ERS Co., Los Altos, CA, USA

${ }^{4}$ Jet Propulsion Lab, California Institute of Technology, Pasadena, CA, USA

\begin{abstract}
A previously developed analytical thermal stress model is used for the assessment of the effect of the glasstransition temperature $\left(T_{q}\right)$ of the underfill encapsulant and the thickness of the underfill-solder composite bond (USCB) on the induced stresses. The calculations were carried out for two $T_{g}$ levels, above and below the operation and testing temperature range for the flip-chip (FC) or the fine-pitch ball-grid-array (FPBGA) assembly with an USCB, and for two thicknesses, $0.05 \mathrm{~mm}$ and $0.1 \mathrm{~mm}$, of the USCB. Calculations indicated that the $T_{g}$ level of the underfill material had a significant effect on the induced stresses: the normal stresses in the USCB with a low-modulus (low $T_{g}$ ) underfill were about half the stresses of the design with high-modulus (high $\left.T_{g}\right)$ underfill, and this was true for both thin $(0.05 \mathrm{~mm}$ thick) and thick (0.1 mm thick) USCB layers. As to the role of the USCB thickness, thicker USCBs exhibit somewhat lower normal stresses, than thin layers, but the effect is insignificant. The maximum predicted shearing stresses occur at the USCB/chip, and not at the USCB/substrate interface. This result is in agreement with the observed, in a number of experiments, delaminations at the USCB/chip interface, and not at the USCB/substrate interface. The obtained data indicate also that (in a way, contrary to the current practice) there is an incentive for using low $T_{q}$ underfills, provided, of course, that their adhesive strength is proven to be sufficient for the lower stress level. This is an important requirement, of course, and might explain why electronic product manufacturers employ mostly high $T_{g}$ underfills. As to the incentive for using thicker USCBs, the increase in this thickness from $0.05 \mathrm{~mm}$ to $0.1 \mathrm{~mm}$ resulted in a minor relief in the normal stress in the USCB for both high and low $T_{g}$ underfills, but led to an appreciable relief in the interfacial stresses at the USCB/chip interface, especially for high $T_{g}$ underfills: the predicted stress relief in this case was as significant as $34 \%$. For low Tg underfills the stress relief was much lower, but still appreciable: about $19 \%$. Thicker USCB layers could be more effective, because, as has been shown in our earlier publications and confirmed experimentally, elevated stand-off heights of solder joint interconnections are able to provide appreciable stress relief in the solder material by making the bonding system more compliant. Indeed, for the thickness of $0.75 \mathrm{~mm}$ (impossible for FC designs, but rather typical for FPBGA systems) the decrease in the normal stress acting in the USCB cross-sections is appreciable, and the decrease in the shearing stress at the USCB/chip interface is as high as $70 \%$ in the case of high $T$ underfill and even higher, $76 \%$, in the case of low $T_{g}$ underfill. The employed analytical stress model used in this analysis can be used for the selection of the adequate underfill material and establishing the appropriate USCB thickness at the design stage. It is noteworthy that, as long as the linear approach is used and the induced stresses are proportional to the change in temperature, the developed model can be used also in situations, when the underfill's $T_{g}$ is between the temperature extremes that the assembly of interest experiences during its accelerated testing and in actual operation conditions.
\end{abstract}

\section{Introduction}

It has been established that FC and FPBGA package designs is an attractive way to pursue, as far as low-cost and high-reliability of IC packages are concerned. There are, however, situations when the acceptable reliability level in FC and FPBGA technologies cannot be achieved without bringing in surrogate materials, underfills, between the chip and its substrate to strengthen the solder joint interconnections. Underfill technology has been suggested, among other possible encapsulation technologies, about three decades ago [1], but has become the technology of choice in the today's IC packaging [2-12]. Solder material fatigue failures because of the inelastic strains in the peripheral portions of the solder joint interconnections and delaminations (typically at the chip-solder interface) were observed as the main failure modes in FC and FPBGA structures with underfills [13-27]. It is expected that the appropriately chosen underfill material and the adequate application technology will improve the situation. First of all, one should determine if it would be possible to get away with an un-encapsulated design ("to underfill or not to underfill?") and still meet the reliability requirements. If an underfill decision is made, one should select the adequate underfill material and technology, with consideration of numerous factors associated with the application of this technology: encapsulation process, time-to-market (completion), cost, manufacturability, testability, reparability, etc.

Some existing experiments show that 1) packages with high- $T$ underfills are less sensitive to the $85^{\circ} \mathrm{C} / 85 \% \mathrm{RH}$ temperature-humidity bias, that 2) high $T_{g}$ underfills lead to somewhat higher induced curvatures than low $T_{g}^{g}$ underfills, that 3) packages with low- $T_{g}$ underfills exhibit during cooling processes appreciable stress relaxation; that 4 ) the final deformations of the packages (this takes place at low temperature

*Corresponding author: Suhir E, Departments of Mechanics and Materials, Electrical and Computer Engineering, Portland State University, Portland, OR 97207, USA, Tel: +650-969-1530; E-mail: suhire@aol.com

Received November 06, 2018; Accepted November 30, 2018; Published December 07, 2018

Citation: Suhir E, Ghaffarian R (2018) Predicted Thermal Stress in Flip-Chip and Fine-Pitch-Ball-Grid-Array Designs: Effect of the Underfill Glass Transition Temperature. J Electr Electron Syst 7: 286. doi: 10.4172/2332-0796.1000286

Copyright: ( 2018 Suhir E, et al. This is an open-access article distributed under the terms of the Creative Commons Attribution License, which permits unrestricted use, distribution, and reproduction in any medium, provided the original author and source are credited. 
conditions, when the difference in the thermal strains between the chip and its substrate is the highest) depend, in low $T_{g}$ underfills, also on the cooling rate, and that 5) the underfill behavior depends not only on the $T_{g}$ level, but also on the width of the $T_{g}$ region and its slope. Zhang $\mathrm{Z}$ et al. conclude that "as long as the accurate temperature-dependent properties of underfill are not used, the predicted solder fatigue life based on a single value of $T_{g}$ and a sharp transition is subject to skepticism" and that the "lifetime variation can be $80 \%$ less for steeper slope and doubled for a shallower slope". This means particularly that the "steep slope" assumption is conservative: it results in a somewhat shorter predicted fatigue life.

In the analysis that follows the role of one important characteristic of the USCB is addressed: the glass transition temperature $\left(T_{q}\right)$ of the underfill epoxy [28-30]. Below $T_{g}$ the epoxy is in a hard (glassy) state. Above the $T_{g}$ it transitions to a rubbery state and, as a result, the material's modulus decreases and its CTE increases. There is also an indication that, for many epoxies, their cohesive and adhesive strength is lower above the $T_{g}$. The latter drawback might be, however, a lesser problem, considering that the applications of a low $T_{g}$ epoxy might lead to considerably lower stresses. In the analysis carried out in the current paper it is shown that this might be indeed the case. The role of the USCB thickness is also assessed. The stresses considered in this analysis include normal stresses acting in the cross-sections of the chip, the substrate, and the USCB, and the shearing stresses at the USCB interfaces with the chip and the substrate. Since the USCB bonding layer is comprised of a relatively high-modulus solder and low-modulus epoxy underfill (even when the underfill epoxy is loaded with fillers), and is characterized therefore, unlike in adhesively bonded joints, by a relatively high effective Young's modulus, a tri- and not a bi-material predictive model [31-33] is employed.

\section{Analysis}

\section{Assumptions}

The following major assumptions were used in this analysis:

-Structural analysis (strength-of-materials) approach can be applied to evaluate the induced stresses, so that no singular stresses can possibly occur at the assembly edges. From the theory-of-elasticity standpoint, the predicted stresses can be viewed as useful design-for-reliability parameters that characterize the state of stress in the bonded assembly of interest, including its edge portions.

-The assembly and its constituents (components) can be treated as thin elongated plates, experiencing small deflections. The engineering theory of such plates can be employed therefore to determine the stresses and the deflections.

-The interfacial shearing stresses and the total assembly curvature can be evaluated without considering the effect of the peeling stresses - normal interfacial stresses acting in the through-thickness direction of the assembly. The peeling stresses, which are proportional to the longitudinal gradient of the interfacial shearing stresses, can be then determined, if necessary, from the evaluated shearing stresses.

-The shearing stresses can be found, based on the concept of the interfacial compliance [34], assuming that the interfacial displacements of the assembly components can be represented as a sum of unrestricted (stress-free) thermal displacements; displacements, predicted using Hooke's law and calculated under an assumption that these displacements are the same for the entire cross-section of the given assembly component; and corrections considering that, in reality, the interfacial displacements are somewhat larger than the displacements of the inner points of the given cross-section. In addition, it is assumed that these corrections are proportional to the interfacial shearing stress in the given cross-section and are not affected by the stresses and strains in the adjacent cross-sections;

-The effect of the assembly bow is not considered in this analysis;

-The dependence of the mechanical properties (Young's modulus and CTE) of the underfill material of temperature is a step-wise function; in other words, the glass-transition temperature $T_{g}$ is characterized by a single number; based on the Zhang $\mathrm{Z}$ information, it is a conservative assumption.

\section{Thermally induced forces and interfacial stresses}

The following formulas can be used for the evaluation of the thermally induced forces and the interfacial shearing stresses [33]:

1. Thermally induced forces in the mid-portion of a long flip-chip/ substrate assembly:

$$
\begin{aligned}
& T_{1}=\frac{\left(\alpha_{1}-\alpha_{2}\right) \lambda_{0}+\left(\alpha_{1}-\alpha_{0}\right) \lambda_{2}}{\lambda_{0} \lambda_{1}+\lambda_{1} \lambda_{2}+\lambda_{2} \lambda_{0}} \Delta t, T_{1}=\frac{\left(\alpha_{1}-\alpha_{2}\right) \lambda_{0}+\left(\alpha_{1}-\alpha_{0}\right) \lambda_{2}}{\lambda_{0} \lambda_{1}+\lambda_{1} \lambda_{2}+\lambda_{2} \lambda_{0}} \Delta t, \\
& T_{2}=\frac{\left(\alpha_{2}-\alpha_{1}\right) \lambda_{0}+\left(\alpha_{2}-\alpha_{0}\right) \lambda_{1}}{\lambda_{0} \lambda_{1}+\lambda_{1} \lambda_{2}+\lambda_{2} \lambda_{0}} \Delta t
\end{aligned}
$$

Here $T_{1}$ is the change in temperature from the elevated (manufacturing) temperature to the low (room, testing, operation, $T$ ) temperature; $T_{0}, T_{1}$ and $T_{2}$ are the thermally induced forces (per unite assembly width) acting in the mid-portion of the (underfilled) solder layer (zero component), the chip (component \#1), and in the substrate (component \#2), respectively; $\alpha_{0}, \alpha_{1}$ and $\alpha_{2}$ are the effective CTE's of the materials; $\lambda_{i}=\frac{1-v_{i}}{E_{i} h_{i}}, i=0,1,2$ are the effective axial compliances of the assembly components; $E_{i}, i=0,1,2$, are the effective Young's moduli of the materials; $v_{i}, i=0,1,2$, are their Poisson's ratios; and $h_{i}, i=0,1,2$ are the assembly component thicknesses.

\section{Distributed thermally induced forces:}

$$
T_{0}(x)=T_{0}\left(1-\frac{\cosh k x}{\cosh k l}\right), T_{1}(x)=T_{1}\left(1-\frac{\cosh k x}{\cosh k l}\right), T_{2}(x)=T_{2}\left(1-\frac{\cosh k x}{\cosh k l}\right)
$$

Here $k$ is half the assembly length, and $k$ is the thus far unknown parameter of the assembly. Here

$$
k=\sqrt{\frac{k_{1}^{2}+k_{2}^{2}}{2}\left[1+\sqrt{1-\delta\left(\frac{2 k_{1} k_{2}}{k_{1}^{2}+k_{2}^{2}}\right)^{2}}\right]}
$$

is the parameter of the interfacial shearing stress,

$$
k_{1}=\sqrt{\frac{\lambda_{0}+\lambda_{1}}{\kappa_{0}+\kappa_{1}}}, k_{2}=\sqrt{\frac{\lambda_{0}+\lambda_{2}}{\kappa_{0}+\kappa_{2}}},
$$

are the "partial" parameters of the interfacial shearing stresses,

$$
\delta=\frac{\lambda_{0} \lambda_{1}+\lambda_{1} \lambda_{2}+\lambda_{2} \lambda_{0}}{\left(\lambda_{0}+\lambda_{1}\right)\left(\lambda_{0}+\lambda_{2}\right)}
$$

is the factor of the axial compliances of the assembly components, $\kappa_{0}=\frac{h_{0}}{G_{0}}$ is the longitudinal interfacial compliance of the solder layer; $G_{0}$ is the effective shear modulus of this layer; $\kappa_{i}=\frac{h_{i}}{3 G_{i}}, i=1,2$ are the longitudinal interfacial compliances of the chip and the substrate, respectively; $G_{i}=\frac{E_{i}}{2\left(1+v_{i}\right)}, i=0,1,2$ are the shear moduli of the components' materials. 
Citation: Suhir E, Ghaffarian R (2018) Predicted Thermal Stress in Flip-Chip and Fine-Pitch-Ball-Grid-Array Designs: Effect of the Underfill Glass Transition Temperature. J Electr Electron Syst 7: 286. doi: 10.4172/2332-0796.1000286

3. Interfacial shearing stresses:

$$
\tau_{1}(x)=\frac{d T_{1}(x)}{d x}=-k T_{1} \frac{\sinh k x}{\cosh k l}, \quad \tau_{2}(x)=\frac{d T_{2}(x)}{d x}=-k T_{2} \frac{\sinh k x}{\cosh k l}
$$

The signs of these stresses depend on the signs of the forces $T_{1}$ and $T_{2}$, and the signs of these forces, whether tensile (+) or compressive (-), are determined by the formulas (1).

The highest shearing stresses take place, in accordance with this model, at the end cross-sections: $\tau_{1}(l)=-k T_{1} \tanh k l, \quad \tau_{2}(l)=-k T_{2} \tanh k l$.

For $k l \succ 2.5$ these stresses become assembly size independent:

$\tau_{1}(l)=-k T_{1}, \quad \tau_{2}(l)=-k T_{2}$.

\section{Computed Data}

Computed Data is shown in the below Tables 1-7.

\begin{tabular}{|c|c|c|c|}
\hline Component \# Properties & 0 (Underfilled solder) & 1 (Chip) & 2 (Substrate) \\
\hline Effective CTE, $\alpha, 1 /{ }^{\circ} C$ & $60 \times 10^{-6}$ & $2.2 \times 10^{-6}$ & $13.2 \times 10^{-6}$ \\
\hline Effective Young's modulus, $E, \mathrm{~kg} / \mathrm{mm}^{2}$ & 2000 & 12300 & 2000 \\
\hline Poisson's ratio, $V$ & 0.40 & 0.24 & 0.30 \\
\hline Shear modulus $G=\frac{E}{2(1+v)}, \mathrm{kg} / \mathrm{mm}^{2}$ & 714.3 & 4959.7 & 769.2 \\
\hline Thickness, $h, m \quad 2(1+v)$ & 0.05 & 0.5 & 1.5 \\
\hline Axial compliance $\lambda=\frac{1-v}{E h}, \mathrm{~mm} / \mathrm{kg}$ & $60.0000 \times 10^{-4}$ & $1.2358 \times 10^{-4}$ & $2.3333 \times 10^{-4}$ \\
\hline Axial compliance factor $F=\lambda_{0} \lambda_{1}+\lambda_{1} \lambda_{2}+\lambda_{2} \lambda_{0}, \mathrm{~mm}^{2} / \mathrm{kg}^{2}$ & \multicolumn{3}{|c|}{$217.0295 \times 10^{-8}$} \\
\hline $\begin{array}{l}\text { Thermal forces, } \mathrm{kg} / \mathrm{mm} \\
T_{0}=\frac{\Delta t}{F}\left[\left(\alpha_{0}-\alpha_{1}\right) \lambda_{2}+\left(\alpha_{0}-\alpha_{2}\right) \lambda_{1}\right] \\
T_{1}=\frac{\Delta t}{F}\left[\left(\alpha_{1}-\alpha_{2}\right) \lambda_{0}+\left(\alpha_{1}-\alpha_{0}\right) \lambda_{2}\right] \\
T_{2}=\frac{\Delta t}{F}\left[\left(\alpha_{2}-\alpha_{1}\right) \lambda_{0}+\left(\alpha_{2}-\alpha_{0}\right) \lambda_{1}\right]\end{array}$ & 150.3194 & -620.0493 & 469.7299 \\
\hline Normal stresses $\sigma=\frac{T}{h}, \mathrm{~kg} / \mathrm{mm}^{2}$ & 3006.3880 & -1240.0986 & 313.1533 \\
\hline $\begin{array}{l}\text { Interfacial compliance, } \kappa \\
\kappa_{0}=\frac{h_{0}}{G_{0}}, \kappa_{1}=\frac{h_{1}}{3 G_{1}}, \kappa_{2}=\frac{h_{2}}{3 G_{2}} \cdot \mathrm{mm}^{3} / \mathrm{kg}\end{array}$ & $0.7000 \times 10^{-4}$ & $0.3360 \times 10^{-4}$ & $6.5003 \times 10^{-4}$ \\
\hline Factor of the relative axial compliance $\delta=\frac{F}{\left(\lambda_{0}+\lambda_{1}\right)\left(\lambda_{0}+\lambda_{2}\right)}$ & \multicolumn{3}{|c|}{0.056858} \\
\hline Chip-to-solder parameter of the interfacial shearing stress $k_{1}=\sqrt{\frac{\lambda_{0}+\lambda_{1}}{\kappa_{0}+\kappa_{1}}}, \mathrm{~mm}^{-1}$ & & 7.6882 & \\
\hline Substrate-to-solder parameter of the interfacial shearing stress $k_{2}=\sqrt{\frac{\lambda_{0}+\lambda_{2}}{\kappa_{0}+\kappa_{2}}}, \mathrm{~mm}^{-1}$ & & & 2.9423 \\
\hline \multicolumn{4}{|l|}{ Parameter of the interfacial shearing stress } \\
\hline$k=\sqrt{\frac{k_{1}^{2}+k_{2}^{2}}{2}\left[1+\sqrt{1-\delta\left(\frac{2 k_{1} k_{2}}{k_{1}^{2}+k_{2}^{2}}\right)^{2}}\right]}, \mathrm{mm}^{-1}$ & & 8.2057 & \\
\hline \multicolumn{2}{|l|}{ Shearing stress at chip-solder interface $\tau_{1}(l)=-k T_{1}, \mathrm{~kg} / \mathrm{mm}^{2}$} & 5087.9305 & \\
\hline \multicolumn{2}{|l|}{ Shearing stress at solder-PCB interface $\tau_{2}(l)=-k T_{2}, \mathrm{~kg} / \mathrm{mm}^{2}$} & & -3854.4626 \\
\hline
\end{tabular}

Table 1: High $T_{g}$ (above the curing temperature), high modulus, low expansion and $0.05 \mathrm{~mm}$ thick underfill. 
Citation: Suhir E, Ghaffarian R (2018) Predicted Thermal Stress in Flip-Chip and Fine-Pitch-Ball-Grid-Array Designs: Effect of the Underfill Glass Transition Temperature. J Electr Electron Syst 7: 286. doi: 10.4172/2332-0796.1000286

Page 4 of 10

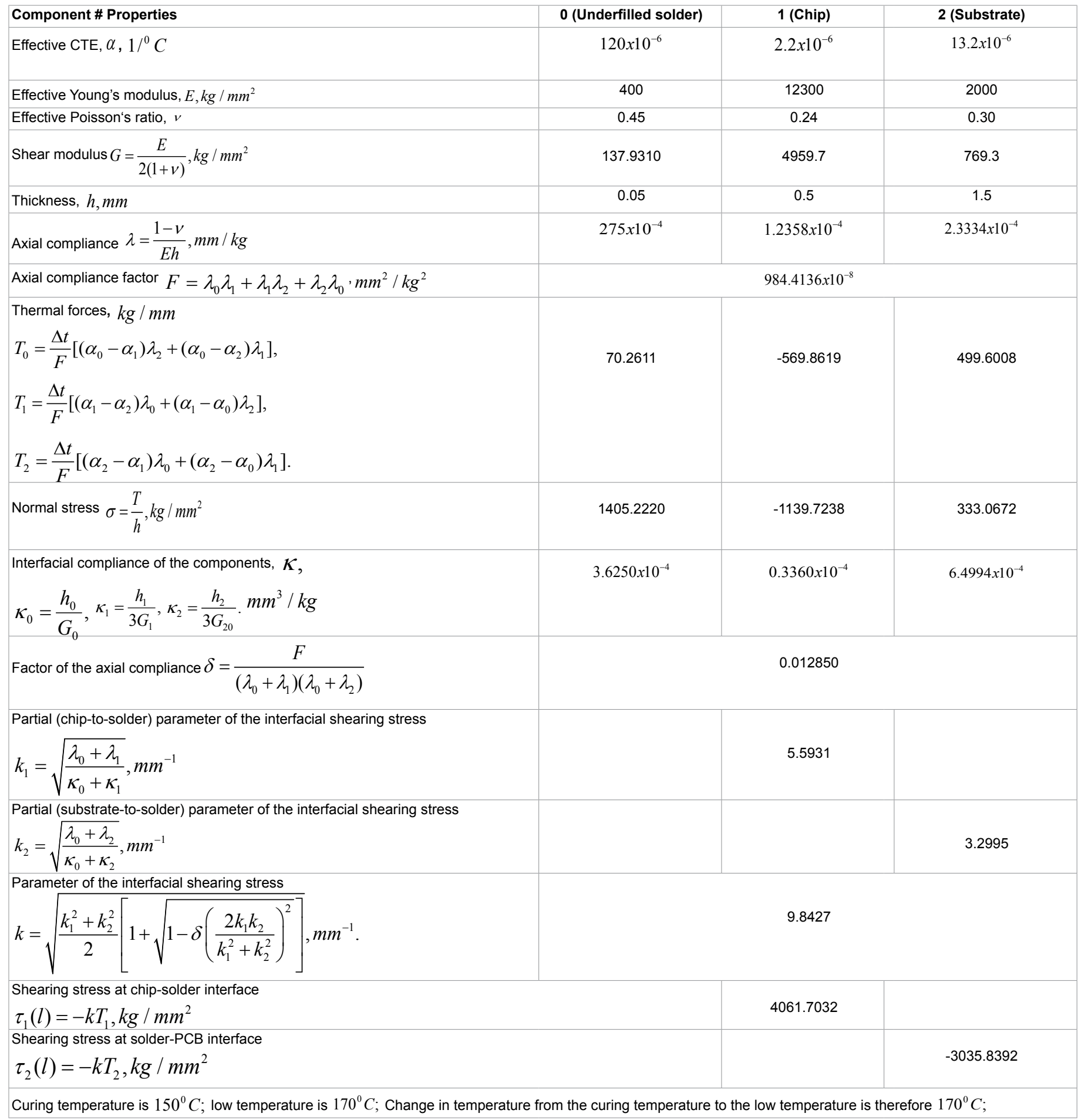

Table 2: Low $T_{g}$ (below the lowest temperature possible), low modulus, high expansion and $0.05 \mathrm{~mm}$ thick underfill.

\section{Conclusions and Future Work}

The following conclusions can be drawn from the calculated data:

- The maximum predicted shearing stresses occur indeed at the USCB/chip, and not at the USCB/substrate interface, and this result is in agreement with the observed delaminations at the USCB/chip interface.
- The calculated data indicate that there is an incentive for using low $T_{g}$ underfills, provided, of course, that their adhesive strength is proven to be sufficient. This might me less of a challenge, even if the cohesive and the adhesive strength of the USCB layer with a low $T_{g}$ is not very high, but the applied stresses are also relatively low.

- $\quad$ As to the incentive for using thicker USCBs, the increase in this thickness from $0.05 \mathrm{~mm}$ to $0.1 \mathrm{~mm}$ resulted in rather minor relief 
Citation: Suhir E, Ghaffarian R (2018) Predicted Thermal Stress in Flip-Chip and Fine-Pitch-Ball-Grid-Array Designs: Effect of the Underfill Glass Transition Temperature. J Electr Electron Syst 7: 286. doi: 10.4172/2332-0796.1000286

Page 5 of 10

\begin{tabular}{|c|c|c|c|}
\hline Component \# Properties & 0 (Underfilled solder) & 1 (Chip) & 2 (Substrate) \\
\hline Effective CTE, $\alpha, 1{ }^{\circ} \mathrm{C}$ & $60 \times 10^{-6}$ & $2.2 \times 10^{-6}$ & $13.2 \times 10^{-6}$ \\
\hline Effective Young's modulus, $E, \mathrm{~kg} / \mathrm{mm}^{2}$ & 2000 & 12300 & 2000 \\
\hline Poisson's ratio, $v$ & 0.40 & 0.24 & 0.30 \\
\hline Shear modulus $G=\frac{E}{2(1+v)}, \mathrm{kg} / \mathrm{mm}^{2}$ & 714.3 & 4959.7 & 769.2 \\
\hline Thickness, $h, m m$ & 0.1 & 0.5 & 1.5 \\
\hline Axial compliance $\lambda=\frac{1-v}{E h}, \mathrm{~mm} / \mathrm{kg}$ & $30.0000 \times 10^{-4}$ & $1.2358 \times 10^{-4}$ & $2.3333 \times 10^{-4}$ \\
\hline $\begin{array}{l}\text { Axial compliance factor } \\
F=\lambda_{0} \lambda_{1}+\lambda_{1} \lambda_{2}+\lambda_{2} \lambda_{0}, \mathrm{~mm}^{2} / \mathrm{kg}^{2}\end{array}$ & \multicolumn{3}{|c|}{$109.9595 \times 10^{-8}$} \\
\hline $\begin{array}{l}\text { Thermal forces, } \mathrm{kg} / \mathrm{mm} \\
T_{0}=\frac{\Delta t}{F}\left[\left(\alpha_{0}-\alpha_{1}\right) \lambda_{2}+\left(\alpha_{0}-\alpha_{2}\right) \lambda_{1}\right], \\
T_{1}=\frac{\Delta t}{F}\left[\left(\alpha_{1}-\alpha_{2}\right) \lambda_{0}+\left(\alpha_{1}-\alpha_{0}\right) \lambda_{2}\right], \\
T_{2}=\frac{\Delta t}{F}\left[\left(\alpha_{2}-\alpha_{1}\right) \lambda_{0}+\left(\alpha_{2}-\alpha_{0}\right) \lambda_{1}\right]\end{array}$ & 297.9190 & -718.6920 & 420.7730 \\
\hline $\begin{array}{l}\text { Normal stress } \\
\sigma=\frac{T}{h}, \mathrm{~kg} / \mathrm{mm}^{2}\end{array}$ & 2979.1900 & -1437.3840 & 280.5153 \\
\hline $\begin{array}{l}\text { Interfacial compliance, } \kappa \\
\kappa_{0}=\frac{h_{0}}{G_{0}}, \kappa_{1}=\frac{h_{1}}{3 G_{1}}, \kappa_{2}=\frac{h_{2}}{3 G_{2}} \cdot \mathrm{mm}^{3} / \mathrm{kg}\end{array}$ & $1.4000 \times 10^{-4}$ & $0.3360 \times 10^{-4}$ & $6.5003 \times 10^{-4}$ \\
\hline Factor of the relative axial compliance $\delta=\frac{F}{\left(\lambda_{0}+\lambda_{1}\right)\left(\lambda_{0}+\lambda_{2}\right)}$ & \multicolumn{3}{|c|}{0.108875} \\
\hline$k_{1}=\sqrt{\frac{\lambda_{0}+\lambda_{1}}{\kappa_{0}+\kappa_{1}}}, \mathrm{~mm}^{-1}$ & & 4.2418 & \\
\hline$k_{2}=\sqrt{\frac{\lambda_{0}+\lambda_{2}}{\kappa_{0}+\kappa_{2}}}, \mathrm{~mm}^{-1}$ & & & 2.0230 \\
\hline \multicolumn{4}{|l|}{ Parameter of the interfacial shearing stress } \\
\hline 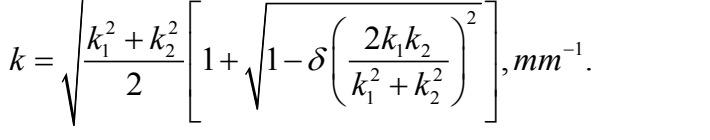 & & 4.6601 & \\
\hline $\begin{array}{l}\text { Shearing stress at chip-solder interface } \\
\tau_{1}(l)=-k T_{1}, \mathrm{~kg} / \mathrm{mm}^{2}\end{array}$ & & 3349.1683 & \\
\hline $\begin{array}{l}\text { Shearing stress at solder-PCB interface } \\
\tau_{2}(l)=-k T_{2}, \mathrm{~kg} / \mathrm{mm}^{2}\end{array}$ & & & -1960.8443 \\
\hline
\end{tabular}

Table 3: High $T_{g}$ (above the curing temperature), high modulus, low expansion and $0.1 \mathrm{~mm}$ thick underfill

in the normal stress in the bond for both high and low $T_{g}$ underfills, but led to an appreciable relief in the interfacial stresses at the USCB/chip interface, especially for high $T_{g}$ underfills. The stress relief for them was as high as $34 \%$. For low $T_{\text {g }}$ underfills the relief was much lower, about $19 \%$. However, for the thickness of $0.75 \mathrm{~mm}$ (impossible for FC designs, but quite typical for FPBGA systems) the decrease in the normal stress 
Citation: Suhir E, Ghaffarian R (2018) Predicted Thermal Stress in Flip-Chip and Fine-Pitch-Ball-Grid-Array Designs: Effect of the Underfill Glass Transition Temperature. J Electr Electron Syst 7: 286. doi: 10.4172/2332-0796.1000286

Page 6 of 10

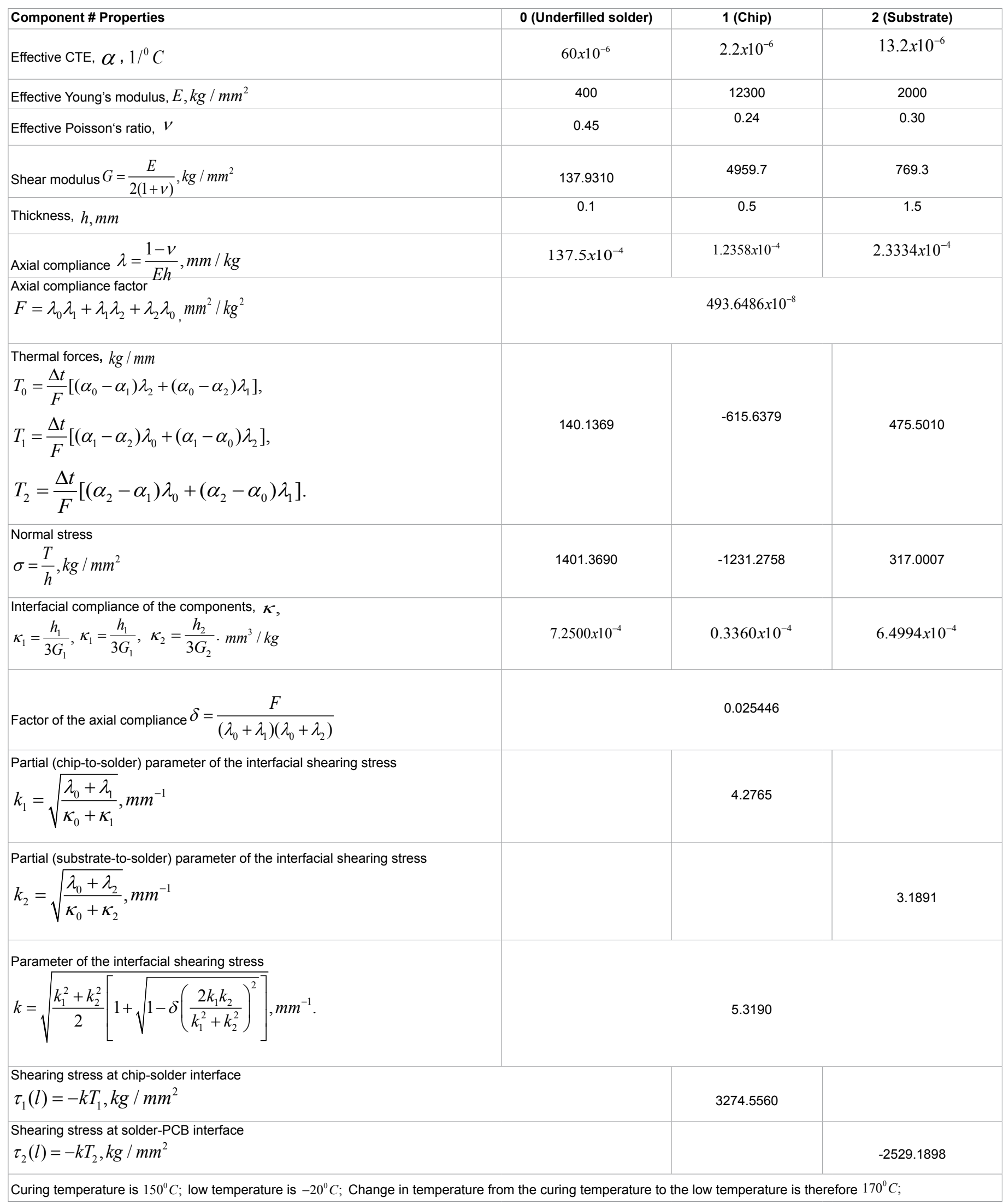

Table 4: Low $T_{g}$ (below the lowest temperature possible), low modulus, high expansion and $0.1 \mathrm{~mm}$ thick underfill. 
Citation: Suhir E, Ghaffarian R (2018) Predicted Thermal Stress in Flip-Chip and Fine-Pitch-Ball-Grid-Array Designs: Effect of the Underfill Glass Transition Temperature. J Electr Electron Syst 7: 286. doi: 10.4172/2332-0796.1000286

Page 7 of 10

\begin{tabular}{|c|c|c|c|}
\hline Component \# Properties & 0 (Underfilled solder) & 1 (Chip) & 2 (Substrate) \\
\hline Effective CTE, $\alpha, 1 /{ }^{0} C$ & $60 \times 10^{-6}$ & $2.2 \times 10^{-6}$ & $13.2 \times 10^{-6}$ \\
\hline Effective Young's modulus, $E, \mathrm{~kg} / \mathrm{mm}^{2}$ & 2000 & 12300 & 2000 \\
\hline Poisson's ratio, $v$ & 0.40 & 0.24 & 0.30 \\
\hline Shear modulus $G=\frac{E}{2(1+v)}, \mathrm{kg} / \mathrm{mm}^{2}$ & 714.3 & 4959.7 & 769.2 \\
\hline Thickness, $h, m m$ & 0.75 & 0.5 & 1.5 \\
\hline Axial compliance $\lambda=\frac{1-v}{E h}, \mathrm{~mm} / \mathrm{kg}$ & $4.0000 \times 10^{-4}$ & $1.2358 \times 10^{-4}$ & $2.3333 \times 10^{-4}$ \\
\hline $\begin{array}{l}\text { Axial compliance factor } \\
F=\lambda_{0} \lambda_{1}+\lambda_{1} \lambda_{2}+\lambda_{2} \lambda_{0}, \mathrm{~mm}^{2} / \mathrm{kg}^{2}\end{array}$ & \multicolumn{3}{|c|}{$17.1604 \times 10^{-8}$} \\
\hline $\begin{array}{l}\text { Thermal forces, } \mathrm{kg} / \mathrm{mm} \\
T_{0}=\frac{\Delta t}{F}\left[\left(\alpha_{0}-\alpha_{1}\right) \lambda_{2}+\left(\alpha_{0}-\alpha_{2}\right) \lambda_{1}\right] \\
T_{1}=\frac{\Delta t}{F}\left[\left(\alpha_{1}-\alpha_{2}\right) \lambda_{0}+\left(\alpha_{1}-\alpha_{0}\right) \lambda_{2}\right] \\
T_{2}=\frac{\Delta t}{F}\left[\left(\alpha_{2}-\alpha_{1}\right) \lambda_{0}+\left(\alpha_{2}-\alpha_{0}\right) \lambda_{1}\right]\end{array}$ & 1909.0414 & -1771.9806 & -137.0608 \\
\hline $\begin{array}{l}\text { Normal stress } \\
\sigma=\frac{T}{h}, \mathrm{~kg} / \mathrm{mm}^{2}\end{array}$ & 2545.3885 & -3543.9612 & -91.3739 \\
\hline $\begin{array}{l}\text { Interfacial compliance, } \kappa \\
\kappa_{0}=\frac{h_{0}}{G_{0}}, \kappa_{1}=\frac{h_{1}}{3 G_{1}}, \kappa_{2}=\frac{h_{2}}{3 G_{2}} \cdot \mathrm{mm}^{3} / \mathrm{kg}\end{array}$ & $10.4998 \times 10^{-4}$ & $0.3360 \times 10^{-4}$ & $6.5003 \times 10^{-4}$ \\
\hline Factor of the relative axial compliance $\delta=\frac{F}{\left(\lambda_{0}+\lambda_{1}\right)\left(\lambda_{0}+\lambda_{2}\right)}$ & \multicolumn{3}{|c|}{0.517496} \\
\hline $\begin{array}{l}\text { Chip-to-solder parameter of the interfacial shearing stress } \\
k_{1}=\sqrt{\frac{\lambda_{0}+\lambda_{1}}{\kappa_{0}+\kappa_{1}}}, \mathrm{~mm}^{-1}\end{array}$ & & 0.6951 & \\
\hline $\begin{array}{l}\text { Substrate-to-solder parameter of the interfacial shearing stress } \\
k_{2}=\sqrt{\frac{\lambda_{0}+\lambda_{2}}{\kappa_{0}+\kappa_{2}}}, \mathrm{~mm}^{-1}\end{array}$ & & & 0.6104 \\
\hline \multicolumn{4}{|l|}{ Parameter of the interfacial shearing stress } \\
\hline$k=\sqrt{\frac{k_{1}^{2}+k_{2}^{2}}{2}\left[1+\sqrt{1-\delta\left(\frac{2 k_{1} k_{2}}{k_{1}^{2}+k_{2}^{2}}\right)^{2}}\right]}, \mathrm{mm}^{-1}$. & \multicolumn{3}{|c|}{0.8531} \\
\hline $\begin{array}{l}\text { Shearing stress at chip-solder interface } \\
\tau_{1}(l)=-k T_{1}, \mathrm{~kg} / \mathrm{mm}^{2}\end{array}$ & & 1511.6946 & \\
\hline $\begin{array}{l}\text { Shearing stress at solder-PCB interface } \\
\tau_{2}(l)=-k T_{2}, \mathrm{~kg} / \mathrm{mm}^{2}\end{array}$ & & & -116.9266 \\
\hline
\end{tabular}

Table 5: High $T_{g}$ (above the curing temperature), high modulus, low expansion and $0.75 \mathrm{~mm}$ thick underfill. 
Citation: Suhir E, Ghaffarian R (2018) Predicted Thermal Stress in Flip-Chip and Fine-Pitch-Ball-Grid-Array Designs: Effect of the Underfill Glass Transition Temperature. J Electr Electron Syst 7: 286. doi: 10.4172/2332-0796.1000286

Page 8 of 10

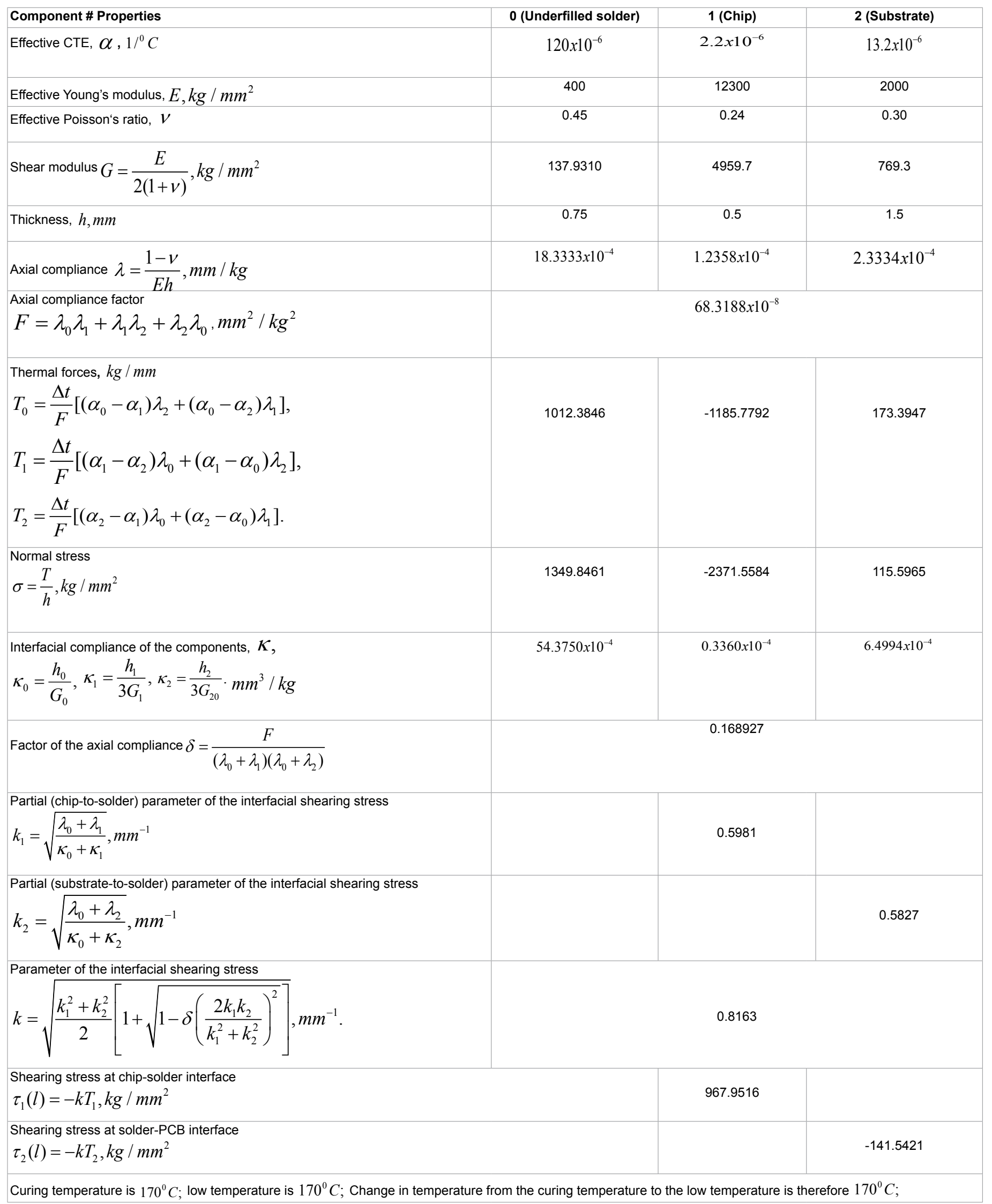

Table 6: Low $T_{g}$ (below the lowest temperature possible), low modulus, high expansion and $0.75 \mathrm{~mm}$ thick underfill. 
Citation: Suhir E, Ghaffarian R (2018) Predicted Thermal Stress in Flip-Chip and Fine-Pitch-Ball-Grid-Array Designs: Effect of the Underfill Glass Transition Temperature. J Electr Electron Syst 7: 286. doi: 10.4172/2332-0796.1000286

Page 9 of 10

\begin{tabular}{|c|c|c|c|c|c|c|c|}
\hline \multirow{2}{*}{\multicolumn{2}{|c|}{ Stress, $\mathrm{kg} / \mathrm{mm}^{2}$}} & \multicolumn{2}{|c|}{$0.05 \mathrm{~mm}$ thick underfill } & \multicolumn{2}{|c|}{$0.10 \mathrm{~mm}$ thick underfill } & \multicolumn{2}{|c|}{$0.75 \mathrm{~mm}$ thick underfill } \\
\hline & & \multirow{2}{*}{$\begin{array}{c}\text { High } T_{g} \\
3006\end{array}$} & \multirow{2}{*}{$\begin{array}{c}\text { Low } T_{g} \\
1405\end{array}$} & \multirow{2}{*}{$\begin{array}{c}\text { High } T_{g} \\
2979\end{array}$} & \multirow{2}{*}{$\begin{array}{c}\text { Low } T_{g} \\
1401\end{array}$} & \multirow{2}{*}{$\begin{array}{c}\text { High } T_{g} \\
2545\end{array}$} & \multirow{2}{*}{$\begin{array}{r}\text { Low } T_{g} \\
1350\end{array}$} \\
\hline \multirow{3}{*}{ Normal stress } & in the underfill $\sigma_{0}$ & & & & & & \\
\hline & in the chip $\sigma_{1}$ & -1240 & -1140 & -1437 & -1231 & -3544 & -2372 \\
\hline & in the substrate $\tau_{1}$ & 313 & 333 & 280 & 317 & -91 & 116 \\
\hline \multirow[t]{2}{*}{ Shearing stress } & at the underfill-chip interface $\tau_{1}$ & 5088 & 4062 & 3349 & 3275 & 1512 & 968 \\
\hline & at the underfill-substrate interface $\tau_{2}$ & -3854 & -3036 & -1961 & -2529 & -117 & -141 \\
\hline
\end{tabular}

Table 7: Calculated stresses.

in the bond is appreciable, and the decrease in the shearing stress at the USCB with the chip is as high as $70 \%$ in the case of high $T_{g}$ underfill and $76 \%$ in the case of low $T_{g}$ underfill.

- Thicker USCB layers could be more affective, because, as has been shown earlier, elevated stand-off heights of solder joint interconnections are able to provide appreciable stress relief in the solder joints by making the bond more compliant. This should be attributed in part to the use of solder joints with elevated stand-off heights [35].

\section{Future work should include}

- FEA evaluations and experimental verification of the obtained information,

- Development of a predictive model for the case when the $T_{g}$ of the underfill is between the curing and the low temperatures, and for the situation when the dependences of the Young's modulus and CTE of the underfill are characterized by a non-zero width of the transition region; in effect, the developed model can be used for that;

- Methodology for the evaluation of the role of the visco-elastic behavior of the underfill material;

- Methodology for the evaluation of the effective modulus and CTE of the USCB layer [35].

\section{Acknowledgements}

Part of the research described in this publication is being conducted at the Jet Propulsion Laboratory, California Institute of Technology, under a contract with the National Aeronautics and Space Administration. Copyright 2018 California Institute of Technology. U.S. Government sponsorship acknowledged. Reza Ghaffarian would like to acknowledge support of the program managers of the National Aeronautics and Space Administration Electronics Parts and Packaging (NEPP) Program for their continuous support and encouragement.

\section{References}

1. Suhir E, Segelken JM (1990) Mechanical behavior of flip-chip encapsulants. J Electr Packaging 112: 327-332.

2. Lau J, Powers-Maloney LM, Baker JR, Rice D, Shaw B (1989) Solder joint reliability of fine pitch surface mount technology assemblies. 7-th IEEE/CHMT Int Electronic Manufacturing Technology Symp San Francisco, CA, USA.

3. Chai K, Wu E, Hsieh R, Tong JY (2002) Challenge of flip chip encapsulation technologies. Proceedings of SPIE, Denver, CO, USA.

4. Ghaffarian R (2012) Underfill Optimization for FPGA Package/Assembly. Jet Propulsion Lab, Pasadena, CA, USA.

5. Suryanarayana D, Hsiao R, Gall TP, McCreary JM (1991) Enhancement of flip-chip fatigue life by encapsulation. IEEE Trans Compon Hybrids Manuf Tech 14: 218-223.

6. Suryanarayana D, Wu TY, Varcoe JA (1993) Encapsulants used in flip-chip packages. 43rd ECTC, Orlando, FL, USA.
7. Clementi J, McCreary J, Niu TM, Palomaki J, Varcoe J, et al. (1993) Flip chip encapsulation on ceramic substrates. IEEE 43rd ECTC, Orlando, FL, USA.

8. Lau JH (1995) Flip Chip Technologies. McGraw-Hill: New York, NY, USA.

9. Wong CP, Lou S, Zhang Z (2000) Flip-the-chip. Science 290: 2269-2270.

10. Lau JH, Chang $C$ (1999) How to select underfill materials for solder bumped flip-chips on low cost substrates? Int J Microcircuits Electron.

11. Nysaether JB, Lundstrom P, Liu J (1997) Measurements of solder bumps lifetime as a function of the underfill material properties. 1-st IEEE Int. Symp on Polymeric Electronics Packaging, PEP ‘97.

12. Chen T, Wang J, Lu D (2004) Emerging challenges of underfill for flip-chip applications. 54th ECTC, Las Vegas, NV, USA.

13. Semmens JE, Adams T (1998) Flip chip package failure mechanism. Solid State Technol.

14. Dudek R, Schubert A, Michel B (2000) Analysis of flip chip attach reliability. 4th Int. Conference on Adhesive Joining and Coating Technology in Electronics Manufacturing, Espoo, Finland.

15. Mercado L, Sarihan V (2003) Evaluation of the die attach cracking in flip-chip PBGA packages. IEEE CPMT Trans 2: 719-723.

16. Hirohata K, Kawamura N, Mukai M, Kawakami T, Aoki H, et al. (2002) Mechanical fatigue test method for chip/underfill delamination in flip-chip packages. IEEE Trans Electron Packag Manuf 25: 217-222.

17. Fan XJ, Wang HB, Lim TB (2001) Investigation of the underfill delamination and cracking in flip-chip modules under temperature cyclic loading. IEEE Trans Compon Packag Tech.

18. Zhai CJ, Blish RC, Master RN (2004) Investigation and minimization of underfill delamination in flip chip packages. IEEE Trans Dev Mater Reliabil 4: 86-91.

19. Kwak JB, Chung S (2012) The effects of underfill on the thermal fatigue reliability of solder joints in newly developed flip chip on module. IEEE I-Therm, San Diego, CA, USA.

20. Rzepka S, Korhonen M, Meusel E, Li CY (1998) The effect of underfill and underfill delamination on the thermal stress in flip-chip solder joints. J Electron Packag 120: 342-348.

21. Su P, Rzepka S, Korhonen M (1999) The effects of underfill on the reliability of flip chip solder joints. J Electron Mater 28: 1017-1022.

22. Lau J, Lee S, Chang C, Ouyang C (2000) Effects of underfill material properties on the reliability of solder bumped flip chip on board with imperfect underfill encapsulants. IEEE CPMT Transactions 23: 323-333.

23. Dutta I, Gopinath A, Marshall C (2002) Underfill constraint effects during thermo-mechanical cycling of flip-chip solder joints. J Electron Mater 31: 253264.

24. Wang T, Lai Y, Wu J (2003) Effect of underfill thermo-mechanical properties on thermal cycling fatigue reliability of flip-chip ball grid array. $\mathrm{J}$ Electron Packag 126: 560-564.

25. Kuo CT, Yip MC, Chiang KN (2004) Time and temperature-dependent mechanical behavior of underfill materials in electronic packaging application. Microelectronics Reliability 44: 627-638.

26. Noh BI, Lee BY, Jung SB (2008) Thermal fatigue performance of SnAgCu chip-scale package with underfill. Mater Sci Eng A Struct Mater 483: 464-468.

27. Tsai MY, Lin YC, Huang CY, Wu JD (2005) Thermal deformations and 
Citation: Suhir E, Ghaffarian R (2018) Predicted Thermal Stress in Flip-Chip and Fine-Pitch-Ball-Grid-Array Designs: Effect of the Underfill Glass Transition Temperature. J Electr Electron Syst 7: 286. doi: 10.4172/2332-0796.1000286

Page 10 of 10

stresses of flip-chip BGA packages with low- and high-Tg underfills. IEEE Trans Electron Packag Manuf 28: 328-337.

28. Chang JY, Huang SSSY, Lee CC, Chuang TC (2015) Influence of glass transition temperature of underfill on the stress behavior and reliability of microjoints within a chip stacking architecture. ASME J Electron Packag.

29. Zhang Z, Park SB, Darbha K, Master RN (2010) Effect of glass transition slope of underfill on solder joint fatigue life. 11th Int. Conference on Electronic Packaging Technology \& High Density Packaging.

30. Suhir E (2017) Flip-chip assembly: is a bi-material model acceptable? J Materials in Electronics 28: 15775-15781.
31. Suhir E (2018) Analytical thermal stress model for a typical flip-chip package design. J Mater Sci Materials in Electronics 29: 2676-2688.

32. Suhir E (2001) Analysis of interfacial thermal stresses in a tri-material assembly. J Appl Phys 89: 3685-3694.

33. Suhir E (1986) Stresses in bi-metal thermostats. ASME J Appl Mech 53: 657660.

34. Suhir E (2015) Analysis of a short beam with application to solder joints: could larger stand-off heights relieve stress? Eur J Appl Phys.

35. Qu J, Wong CP (2002) Effective elastic modulus of underfill material for flipchip applications. IEEE CPMT Trans 25: 53-55. 